\title{
SOME EFFECTS OF SHEEP URINE ON PASTURE
}

\author{
W. R. DALE, Department of Agriculture, Wellington
}

A good deal of study into the effects of stock excrement on pastures has been carried out by Sears and his co-workers ( 1942, 1948, 1953), and Doak (1952) has investigated chemical changes in sheep urine. Little recent work, however, has been published on certain aspects of naturally voided sheep urine. This paper sets out some preliminary observations of the effects of sheep urine on pasture and its influence on soil test.

The findings are restricted to one soil type, the Judgeford silt loam, a greywacke derived soil classified by Gibbs (1960) as a "brown friable silty loam over brownish yellow firm silty loam". The pasture was a poor sward comprising Danthonia pilosa, Festuca rubra (chewings fescue), Agrostis tenuis (browntop), and Anthoxanthum odoratum (sweet vernal), with many flatweeds, mainly Cerastium glomeratum (mouse-eared chickweed), Hypochaeris radicata (catsear), and a little Lolium perenne (perennial ryegrass). In general clovers were not common. The pasture has not been topdressed for 20 years. The climate is typical of the Wellington area with 42 in. of rain (four-yearly average) and exposed to both northerly and southerly winds.

There is little doubt that these conditions, as well as the stock management, play a part in the long-term effects of voided urine, and the results of these experiments may not be entirely valid for other pastures, climate, fertility levels, and stock and farm management.

The experimental technique employed was as follows:

Shortly after the urine was voided the spots were marked and cages placed over them to exclude stock. Any dung that was present was removed. After 2-1-3 days the first soil samples were taken. Doak (1952) has shown that this was the time needed to reach an interim $\mathrm{pH}$ equilibrium at the soil surface. The swards on the urine spots were individually assessed before soil sampling. These soil samples were taken at approximately monthly intervals for at least three months and in some cases for much longer than that. Where possible both visual inspection of the spots and soil sampling continued until there was no visible difference between the majority of any series of spots and the surrounding herbage.

From earlier work we knew that, depending on temperature and humidity, a sward may show no effect whatever from a urination, or it may be killed. A whole range of different effects lies between 
these extremes. We found also that there are two distinct zones associated with the area of the sward on which the urine falls. The first is the area wetted by the urine-the urine spot itself. This coincides with the area of burnt or stained pasture observed a day or two after voiding. Around this spot is an annular zone which, depending on slope, may be a circular ring or it may be drop shaped, extending almost entirely downhill. We call this the annular growth response zone. Beyond this annular zone the area is regarded as an unchanged control.

The seasonal pattern of growth response to urine in these areas was fairly clear.

In spring, although urine frequently burnt the pasture, the annular area around the spots responded within a fortnight and usually grew over the spot, soon hiding it. Urine applied in summer gave bad burning which left some spots bare for 9-10 months. In others pasture responded outside the spot six-eight weeks later. Pasture responses, however, were small and flatweeds usually replaced the killed turf. Urine deposited in autumn showed less burning but took longer (four to five weeks) to respond than in the spring. The main plant species responding was chewings fescue rather than browntop or danthonia, the fescue becoming dark green with slightly increased height. This effect lasted three-four months. In winter, responses were delayed for nearly two months, but growth came away in the spring.

It is clear that the most useful responses were in spring and autumn, and urine deposited in summer or winter did not usually give the best responses until the next season. In all seasons some patches remained bare throughout the period of inspections.

The sward we worked on was very variable and it was not possible to arrange voiding on a range of species to measure the responses of each directly. Nor was it possible in this experiment to measure the responses to urine at different fertility levels. It is very likely that the responses on this soil were limited because of the low phosphate status. This soil responds strongly to lime and superphosphate and slightly to molybdenum. Species which were killed and which responded were noted, although this could not be done for all series. The short-growing, tough species like danthonia and chewings fescue tended to be more resistant to burning than the taller, faster growing, lusher species like ryegrass. On the other hand where ryegrass was present it gave a larger and more vigorous response than the poor species, which did little more than register a colour change. From this it became clear that if the more productive species are not present in the sward, little growth response to urine can be expected. What part stock excrement plays in retaining even the relatively poor components in 
the sward, however, has not been examined. Although urine may give little added growth, it may prevent excessive depletion of the soil minerals on poor quality land, although we have no evidence of this.

If there is little or no response by the sward, this could mean a considerable loss of the nutrients voided in urine over the whole country. The total number of sheep in New Zealand is about 50 million and each of these sheep may void about $6 \mathrm{lb}$ of urine a day (based on Grassland's figures). Something over two million tons equivalent of sulphate of ammonia and a little under $\frac{3}{4}$ million tons of muriate of potash are returned annually by our sheep population. The values of 0.9 per cent nitrogen and 0.7 per cent potassium have been used as approximate average analyses of urine for this calculation.

Of course many factors such as variations in pasture type, in soil, and in climate will affect the calculations. Not all of the urine is wasted by failing to give increased pasture growth. Nonetheless, these figures are only a first approximation. If we were buying this $2 \%$ million tons of fertiliser, would we be complacent about its fate?

Recently several workers in New Zealand have investigated the fate of nutrients in cow urine, in particular the fate of potassium and nitrogen. During (1961), Saunders and Metson (1959), as well as Hogg (1960), McNaught (1958), and others have carried out a number of pot and field trials. These workers have based their investigations on hand applications; we have used the naturally voided urine from sheep.

In this investigation the quick test method of soil analysis (Waters 1953, Davies 1953) has been used for most of the samples. This may not be an entirely satisfactory method, but because of the considerable number of assays required and the preliminary nature of the study, it was felt that these values would suffice.

In Table 1 are the $\mathrm{pH}$ and potassium values of a mowing trial close to the area used for this experiment. The vaiues are typical for this soil type under the fertility conditions indicated earlier.

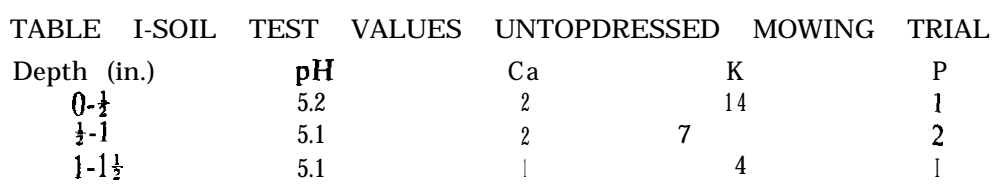

In Table 2 the values for bulked samples of urine spots are given and show changes for both $\mathrm{pH}$ and $\mathrm{K}$. (Under the quick test procedure values over 40 units are not normally recorded.) 
TABLE 2-SOIL TESTS OF URINE SPOTS SAMPLED THE SAME DAY AND THREE DAYS AFTER VOIDING (MEAN OF FOUR

\section{Same Day}

Depth (in.)

$$
\begin{aligned}
& 0-\frac{1}{2} \\
& :-1 \\
& 1-1 \frac{1}{2}
\end{aligned}
$$

\section{$\begin{array}{ll}\text { THREE DAYS AFTER VO } & \text { SAMPLES) }\end{array}$}

Three Days Later

$\begin{array}{llccc}0-\frac{1}{2} & 6.6 & 3.5 & >40 & 2.3 \\ \mathrm{~B}-1 & 5.4 & 3.3 & 17.0 & 1.0 \\ 1-1 \frac{1}{2} & 5.2 & 3.3 & 11.5 & 1.0 \\ 1 \frac{1}{2}-2 & 5.3 & 3.3 & 10.0 & 1.0\end{array}$

These values suggest that the surface $\mathrm{pH}$ increases very rapidly at first. Potassium migrated to at least $2 \mathrm{in}$. in the same day, even under dry soil conditions (sampled $31 / 3 / 60$ ).

The values of available nitrogen were also estimated on a few samples taken from three-day-old spots under dry soil conditions. These are given in Table 3 and confirm the rapid downward movement of urine and show that it can be detected to perhaps 3 in. almost within hours.

TABLE 3-AVAILABLE NITROGEN VALUES INSIDE AND OUTSIDE THE URINE SPOT AREA (EXPRESSED AS PARTS PER MILLION)

Depth (in.)
$0-\frac{1}{2}$
$3-1$
$1-1 \frac{1}{2}$
lf-3

Inside
Available N
545
315
102
80
Outside (control) Available $\mathrm{N}$ 365 205

As seasonal differences in soil test were not marked, sampling of all the series after three months was not considered necessary. The general trend of soil tests for potassium inside the urine spot is for the test to increase immediately to something over 40 units. This level declined slowly to about 20-30 units over three months as shown in Table 4.

There was also an immediate increase in $\mathrm{K}$ values down to 2 in. and sometimes to $3 \mathrm{in}$., and these values tended to remain at about 7-15 units or more for at least three months. For the summer treatments values were still high in the top $2 \mathrm{in}$. when sampling ceased at seven months and in the winter treatments up to twelve months.

In the annular growth response zone immediately surrounding the urine spot, which is about 1 in.-2 in. wide, the K levels increased in the top $\frac{1}{2}$ in. and also after a lag of about a month in the next $\frac{1}{2}$ in. These values returned to normal in about three months. 
TABLE 4-TREND OF POTASSIUM SOIL TESTS FOR SUMMER TREATMENT LAID DOWN 6/2/59

Date Sampled

Depth (in.)

$\begin{array}{cc}\text { Inside } & 0-\mathrm{t}- \\ \text { Urine Spot } & \frac{1}{2}-1\end{array}$

$\frac{1}{2}-1$
$1-1 \frac{1}{2}$
$1 \frac{1}{2}-2$

Annular O-I

Response

Zone

Outside

Control

$\frac{1}{2}-1$
$1-1 \frac{1}{2}$
$1 \frac{1}{2}-2$
$0-\frac{1}{2}$
t-1
$1-1:$
$1 \mathrm{t}-2$

$9 / 2 / 59$

\begin{abstract}
$13 / 3 / 59 \quad 9 / 4 / 59$
\end{abstract}

$\begin{array}{rlllll}> & \mathrm{B} & \mathrm{A} & \mathrm{B} & \mathrm{A} & \mathrm{B} \\ > & >40 & 36 & >40 & 38 & >40 \\ 40 & 22 & 23 & 27 & 31 & 26 \\ 27 & 6 & 14 & 12 & 15 & 15 \\ 13 & 6 & 11 & 11 & 13 & 10\end{array}$

$12 / 5 / 59 \quad 12 / 6 / 59 \quad 15 / 7 / 59$

AB

$\begin{array}{ll}\mathrm{AB} \\ 28 & 22\end{array}$

AB

$13 / 8 / 59$

$\begin{array}{llll}15 & 17 & 22 & 14 \\ 14 & 13 & 16 & 20\end{array}$

$\begin{array}{lll}1914 & 1513 & 1912\end{array}$

$\begin{array}{lllll}1613 & 11 & 11 & 15 & 11\end{array}$

$1110 \div-$

1927

1025

$2222 \quad 1814$

$\begin{array}{ll}17 & 18 \\ 14 & 11\end{array}$

$\begin{array}{ll}14 & 11 \\ 14 & 11\end{array}$

$\begin{array}{ccccccc}711 & 10 & 9 & 11 & 6 & 14 & 11\end{array}$

$\begin{array}{llll}1319 & 1514 & 911 & 1716\end{array}$

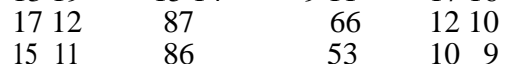

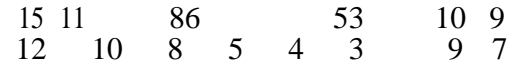

$21 / 9 / 59$

A B C D

$\begin{array}{lllll}20 & 18 & 16 & 19\end{array}$

$\begin{array}{llll}20 & 13 & 13 & 15\end{array}$ 16121316

1410

107

107

$\begin{array}{ll}9 & 8\end{array}$

$\begin{array}{rr}11 & 11 \\ 8 & 7 \\ 7 & 7\end{array}$

Note: Samples $\mathrm{C}$ and $\mathrm{D}$ of $13 / 8 / 59$ and $21 / 9 / 59$ were laid down $6 / 2 / 59$ but not sampled until date indicated. This suggests that drawing inch sample cores from the spots on seven previous occasions has not altered the soil tests noticeably. 
Samples drawn from a third zone outside the annular response zone were regarded as a control and showed only the variation which we would expect in normal field samples. There was no evidence of these soil tests being affected by urine in this zone, whereas there appears to have been some lateral spreading in the growth response zone. It was formerly thought that growth responses in this middle zone were due to underground roots obtaining nutrients from within the urine spot. This cannot now be held to be the exclusive reason for the pasture response in the annulus.

It is postulated therefore that the urine affects the soil in the form of a squat inverted cone with a fairly broad brim round the top. The brim may be only an inch or so deep and 1 to 2 in. wider all round than the actual wetted area, but the main cone may be at least 3 in. deep.

\section{Summary}

The sheep urine spot, as we have observed it, is by no means uniform over the affected area. Urine may stimulate growth, usually outside the confines of the area actually covered by the urination, or it may kill the pasture, depending on climate and other factors. It has marked effects on soil tests at different depths and in different parts of the areas studied. The high concentrations of nitrogen and potassium which fall on a restricted area highlight its potential as a source of these minerals. Although much of this mineral fertility may be lost directly through leaching, especially where the plant cover has been killed, with adequate topdressing and oversowing to introduce the better species into the sward more use would be made of stock urine than when it falls on poor quality swards devoid of productive species.

\section{ACKNOWLEDGMENTS}

The author wishes to thank the staff of Galloway Laboratory, Rukuhia Soil Research Station, for soil tests and Mr P. B. Lynch and staff for advice and help in preparing this manuscript.

\section{R E F E R E N C E S}

Davies, E. B. 19.53: N.Z. J. Agric. 87: 306-312.

Doak, B. W. 1952: J. Agric. Sci. 42: 162-171.

During, C. 1961: In press.

Gibbs, H. S. 1960: Proc. N.Z. Soc. Soil Sci. 4: 4-6.

Hogg, D. E. 1960: N.Z. J. Agric. Res. 3: 377-383.

McNaught, K. J. 1958: N.Z. J. Agric. Res. 1: 148-181.

Saunders, W. M. H. and Metson, A. J. 1959: N.Z. J. Agric. Res. 2: $1211-1231$.

Sears, P. D. and Newbold, R. P. 1942: N.Z. J. Sc. Tech. 42: 36A-61A.

Sears, P. D. and Goodall, V. C. 1948: N.Z. J. Sci. Tech. 30: 231-250.

Sears, P. D. and Thurston, W. G. 1953: N.Z. J. Sci. Tech. 34: 445-459.

Sears, P. D., et al, 1953: N.Z. J. Sci. Tech. 35: Supp. 1, 1-68.

Waters, D. F. 1953: N.Z. J. Agri. 86: 362-363. 